\title{
Effects of vibrissal amputation on cricket predation in northern grasshopper mice (Onychomys leucogaster)
}

\author{
ERNEST D. KEMBLE and CAROLINE LEWIS \\ University of Minnesota, Morris, Minnesota 56267
}

The role of the vibrissae in cricket predation was examined in northern grasshopper mice (Onychomys leucogaster). Vibrissal amputation greatly increased kill latencies but had no effect on latency to initiate pursuit or on killing and consummatory behavior. The increased kill latencies resulted from repeated failures to pin the cricket with the forepaws and seemed to reflect disrupted timing of pouncing when the cricket was within $1-3 \mathrm{~cm}$ of the mouse. Vibrissal stimulation differs from audition, vision, and olfaction in its contribution to the integration of grasshopper mouse predatory behavior.

Grasshopper mice (genus Onychomys) are unusual among rodents in their specializations for a predatory life-style (Bailey \& Sperry, 1929; Baxter, 1979; Flake, 1973), which includes prey with formidable defenses (Cyr, 1972). Langley (in press) has shown that elimination of audition, vision, or olfaction disrupts cricket predation in O. leucogaster. Both vision and audition seem to be of greater importance in guiding predatory attack from a distance, whereas olfaction is particularly important when the mouse is in close proximity to the prey. Previous observations in this laboratory (Kemble, Note 1) suggested that the vibrissae are also important for insect predation by both rats and grasshopper mice. The present experiment examines the role of vibrissal stimulation in the predatory behavior of northern grasshopper mice.

\section{METHOD}

Fourteen adult northern grasshopper mice (O. leucogaster) weighing $30.0-48.9 \mathrm{~g}$ at the beginning of the experiment were tested. The mice were housed and tested in $50 \times 25 \times 29 \mathrm{~cm}$ aquaria containing commercial clay litter. Purina Lab Chow and water were available ad lib throughout testing. Predation testing was conducted by releasing an adult cricket ( $A$. domesticus) in the end of the aquarium opposite to that occupied by the mouse and recording the latency to begin pursuit, kill, and complete consumption of the cricket. Tests were conducted at 24-h intervals. All mice received four daily predation tests and then were assigned to experimental $(\mathrm{N}=7)$ or control $(\mathrm{N}=7)$ groups, which were balanced for initial kill latencies. Experimental mice were then lightly anesthetized with ether, and the vibrissae were trimmed down to $1-2 \mathrm{~mm}$. Control mice were simply anesthetized. Testing resumed $24 \mathrm{~h}$ later and was continued for 3 days.

The authors wish to thank William Langley, who supplied the breeding colony of grasshopper mice. Please send reprint requests to E. D. Kemble.

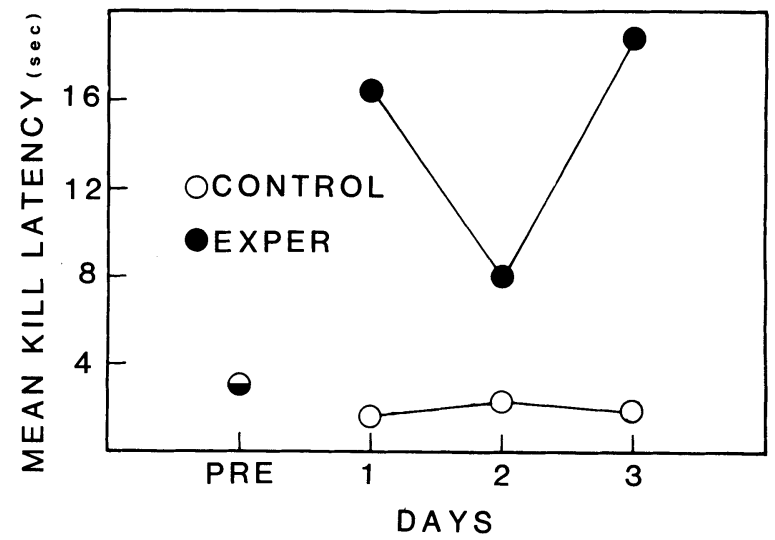

Figure 1. Mean preoperative (PRE) and postoperative kill latencies of mice with intact (Control) or amputated (Exper) vibrissae.

\section{RESULTS AND DISCUSSION}

Normal cricket predation in grasshopper mice begins with rapid sniffing and exploration soon after the cricket is released. When the mouse comes within a few centimeters of the cricket, it orients toward the prey, pursues it rapidly, pounces on its dorsal side, and delivers a series of rapid bites to the head and/or anterior thorax. The cricket's head is then bitten off and the body (except for wings and legs) consumed.

Analyses of variance revealed no group differences in latency to initiate pursuit (means $=1.33-5.34 \mathrm{sec}, \mathrm{p}>$ $.10)$. Once the cricket was killed, there were also no differences in consumption time (means $=1.5-3.6 \mathrm{~min}$, $\mathrm{p}>.10$ ). As can be seen in Figure 1, however, vibrissal amputation greatly increased kill latencies among the experimental mice. Analysis of variance revealed a significant overall effect of vibrissal amputation $[F(1,12)$ $=10.80, \mathrm{p}<.01]$. The elevated kill latencies resulted 
from the repeated failure of experimental mice to pin the cricket. The pounce, which is normally followed by pinning and killing, appeared to be poorly timed, occurring just after a jump by the cricket. These mistimed pounces often continued until the cricket was chased into a corner. Once pinning occurred, both killing and consumption proceeded normally.

The present experiment clearly demonstrates the importance of vibrissal stimulation in the predatory behavior of $O$. leucogaster. Moreover, this effect seems to be restricted to the timing of the pounce that normally precedes killing and consumption. Thus, while both audition and vision (particularly audition) seem important for detection of prey at a distance (Langley, in press), both olfaction (Langley, in press) and vibrissal stimulation become increasingly important in close proximity to the prey. Further observations (Langley, Note 2; Kemble \& Lewis, Note 3) suggest that olfaction contributes to the orientation of the killing bite and prey consumption, as well as prey localization. Thus audition, vision, olfaction, and vibrissal stimulation contribute in distinctive ways to the integration of predatory behavior in this species.

\section{REFERENCE NOTES}

1. Kemble, E. D. Effects of vibrissal amputation on insect predation by rats and northern grasshopper mice. Unpublished observations, 1981.

2. Langley, W. M. Personal communication, 1982.

3. Kemble, E. D., \& Lewis, C. Effects of olfactory bulbectomy on cricket predation in the northern grasshopper mouse. Unpublished observations, 1982.

\section{REFERENCES}

Bailey, V., \& Sperry, C. C. Life history and habits of grasshopper mice, genus Onychomys. Technical Bulletin, U.S. Department of Agriculture, 1929, 145, 1-19.

BAXTER, C. Cricket predation by the northern grasshopper mouse. Behavioral and Neural Biology, 1979, 27, 201-213.

CYR, M. A. Predatory behavior of the grasshopper mouse. Unpublished doctoral thesis, University of California, Los Angeles, 1972.

FLAKE, L. Food habits of four species of rodents on a shortgrass prairie in Colorado. Journal of Mammology, 1973, 54, 634-647.

LANGLEY, W. M. Role of distance senses in the predatory behaviour of the northern grasshopper mouse. Animal Behaviour, in press.

(Received for publication September 30, 1982.) 